\title{
Introduction
}

This book is concerned with both an analysis of the legal institution known as 'copyright', and with the scientific domain of 'economics', or perhaps more correctly, 'economic theory'. If you come from an academic background of strictly legal scholarship, you might well wonder what economics might have to do with a legal concept. Is it not that economics deals with the analysis and prediction of such things as inflation, unemployment, and exchange rates, while copyright is a fundamental property right in intellectual creations? What can the former tell us about the latter? The answer lies in the fact that economics is actually a far wider science than just a consideration of the macroeconomic data generated within an economy. Economics is concerned above all with the efficient functioning of markets. At the micro level, economists study the incentives that determine the choices made by economic agents (consumers and producers, regulators, and so on), and at the aggregate level economics is concerned with the often poorly defined and understood concept of 'social welfare'. The link between economics and copyright becomes clearer when we understand copyright not so much as a fundamental property right alone, but rather as an incentive mechanism that is designed to encourage creative activities, and to ensure that the outputs of creative activities are able to be efficiently transacted in standard market environments, so that they may, in the end, be enjoyed by consumers. In that sense, copyright is a mechanism that might allow more (and perhaps more valuable) outputs to be produced, and allow those outputs to be more easily consumed. Both of these outcomes have the final effect of increasing the utility of the economic agents in the economy, and thus under most standard definitions, social welfare would also be increased. Thus, in a nutshell, economic theory views copyright as a mechanism by which social welfare may be increased.

If one looks at the development of copyright, there are two strands along which the legal concept has travelled. The first of these is the straightforward idea that whatever a person manages to produce, using his or her own ingenuity and abilities, should naturally belong to that same person. Even though the output of this sort of intellectual creative process (a story, a song, a poem, a drawing, and so on) is not necessarily a tangible, visible thing (at least perhaps until it is fixed onto some sort of tangible medium - a physical book, a music $\mathrm{CD}$, and so on), it can still 


\section{Handbook on the economics of copyright}

clearly be considered to be an item of property, similar in all other respects to any other item of property (such as houses, cars and money). Given that perspective, one is led to the conclusion that just as in the case of tangible property, laws should exist that protect the property that is the output of intellectual creativity from theft and general misuse by non-owners. The relevant property right is, of course, known as copyright. ${ }^{1}$ This concept of copyright, as a fundamental property right, was originally championed by John Locke (and therefore it often goes by the name of 'Lockean property right theory'), and this conceptualisation of copyright has little to do with economics, and thus is not of particular relevance to the present book. ${ }^{2}$

The second rationale for a property right in the outputs of intellectual creativity is based squarely upon a standard economic theory of incentives, and of costs and benefits. This point of view is enshrined in the enactment of the concept of copyright in the Constitution of the United States of America, and was also certainly in the minds of the original enactors of the early copyright statutes in Europe. The emphasis of this perspective shifts to the economic value of the creative good, and how it can be successfully moved along the value chain, from its production until it is ultimately able to be consumed and thereby generate utility. If there were no enforced property right in the creation, it could not be easily taken to market, and in that case the creator would unlikely be able to capture the value of the creation from those who would like to benefit from having access to it (the consumers). And if that were to be the case, then perhaps fewer creative individuals would bother to create fewer valuable creations, and everyone who enjoys such creations would be worse off for having fewer of them to consume. Society in general would suffer relative to a situation in which creativity flourished. Thus, a property right appears to be in order, but not for the same fundamental justice reasons as championed by Lockean theory, but rather simply because having such a property right should ultimately lead to greater social welfare as creators are given the incentive to create more (and perhaps better) outputs, and consumers are provided with a means of obtaining access to these outputs.

Similarly to the Lockean perspective, the incentive-based rationale for copyright also begins with the idea that, at least in the first instance, the output (actually, only 'most' of the output - see the next paragraph) of an act of intellectual creativity should belong to the creator. After all, once an item of property has been produced and therefore exists, it must belong to someone. Economists view ownership as a bundle of rights that determine what someone may do with some well-defined item of property. For example, some of the rights would include the right to possess, to use, to develop, to improve, to transform, to sell, to rent, to deplete, to destroy, to donate and to bequeath. Above all, ownership implies the right to exclude 
others from these same acts upon the property in question, and likewise the right to include others at a price (for example, the right to rent transfers the right to possession). ${ }^{3}$ The law is designed to protect the free exercise of property rights from interference by others. Without the concept of ownership, meaningful transactions (which are the vehicle for realising economic value) would be impossible. ${ }^{4}$ But now there is a further, and extremely important, difference with the Lockean rationale for copyright, and indeed with practically any other form of legally recognised property right. The concept of ownership of the creation disappears after a set period of time has passed, and the property in question falls into the 'public domain'. The owner of the property right at that moment of time suddenly loses all rights in the creation, and it thereafter belongs equally to each and every current and future individual or firm. Such a concept of social ownership of course destroys any market for the creation itself, and so everyone is able to freely and legally access all of the rights in the creation in full. ${ }^{5}$ Again, it is efficiency that mandates that copyright is time limited. The copyright is granted so that end consumers can contribute to rewarding the creator for his/her creative efforts, but once enough reward has been gathered (at least in present expected value) for the creation to be brought into existence, any further payments are redundant as far as the objective behind the grant of copyright is concerned. So at that point there is no further need for the copyright to continue to exist, and so it should not continue to exist.

As mentioned in the previous paragraph, not only does the property right expire after some specified passage of time, there are also further restrictions on the rights that are conferred to the creator (and any subsequent right holder) right from the start. These restrictions are known as 'fair use', and they amount to some of the original rights that are born along with the creation being assigned in the first instance and for evermore to the public domain. Again, a property right with this type of structure does not happen in Lockean theory (or indeed in any other property right that I know of), and again a justification for such a structure can be found in economic theory; specifically the efficient functioning of markets and simple cost-benefit analysis. ${ }^{6}$

The economic theory of copyright is centred upon attempting to balance the different effects that the property right has upon both sides of the market for creative goods. Aside from some early articles (for example, Plant, 1934; Hurt and Schuchman, 1966; and Breyer, 1970), the economics literature dedicated to the concept of copyright began in earnest in the early to mid-1980s with a small series of papers in the Journal of Political Economy, and since then it has ballooned out to include what must be by now several thousand relevant papers. ${ }^{7}$ The present book does not purport to cover all of the areas of copyright that have been touched, and 
perhaps shaped in some way, by economic analysis and by economists more generally, but it does give a flavour of a relevant selection of the principal areas. Specifically, here we include chapters on the basic economic theory of copyright, the law and economics perspective, licensing and authorial incentives, copyright collectives, piracy, parallel trade and open source.

The chapters have all been written under the brief of providing a useful basis for classroom discussion, in courses $^{8}$ (which may well be either in economics or law departments) designed to analyse the institution of copyright through the lens of economic theory. To that end, the chapters are not designed to be original research papers, but neither are they designed to be simple surveys of the literature. The idea is to first present the main ideas and arguments from the literature that are relevant to the particular chapter, and then to provide a discussion (or perhaps an application, or an example, or maybe a simplification) of those ideas and arguments in such a way that students of this subject can gain a deeper understanding of the state of the art. Above all, the book is designed to be a useful classroom tool for both students and their teachers. ${ }^{9}$

\section{NOTES}

1. Of course, there is a legal difference between the acts of authorship, which generate creations that contain valuable expression of some sort (of the essence in this book) and acts of innovation, which generate valuable ideas of some sort (which are protected by patent, and which fall outside of the subject matter of this book), both of which are the fruit of intellectual efforts. Here, we associate with acts of 'creativity' only the authorship of copyrightable expression. See Chapter 3 for further discussion on this point.

2. While the Lockean perspective will not be scrutinised in this book, it can still be subject to an economic analysis. After all, the conclusion that laws to protect any sort of property from theft and misuse by non-owners are a good idea in a civilised society must be based upon the realisation that the existence (and enforcement) of such laws leads to a better social outcome from the perspective of social welfare than if the laws were not present (in which case a state of civil anarchy might ensue, with owners having to find other private mechanisms of protecting their property from the evil clutches of others).

3. Notice that rights can be transacted independently of each other, so for example, while a renter might get the right to possess and to use, he would not have the right to sell or to destroy the property.

4. This simple but powerful idea lies at the heart of the theory of Ronald Coase (see Coase 1960).

5. There is a small caveat in place. The original author of the original work can never cease to be thus recognised. This is known as a 'moral right'. So when a work falls into the public domain, it may be modified and transformed by others, and those new creators have the right to be recognised as the authors of the transformed work, but the authorship of the original work can never be altered. In short, no one can ever claim authorship of a work that they did not themselves create.

6. In Chapter 4 Wendy Gordon explains the concept of fair use, and points out why such a restriction on the property right makes good economic sense. 
7. Several surveys exist of specific areas within what has become known as the economics of copyright. See, for example, Liebowitz and Watt (2006), Handke and Towse (2008), and Towse, Handke and Stepan (2008).

8. No attempt has been made to restrict the level of the analysis to undergraduate courses, or to attempt to present material specifically of use for post-graduate students. Some chapters will likely be of greater relevance to undergraduate courses, and others to postgraduate courses, but all of the chapters should contain information that is of use to all students at all levels of study.

9. That said, the book is not a 'textbook' as such. Rather it is a collection of chapters, written by researchers and teachers of the material, that attempt to present the basics of a series of important topics within the economics of copyright in a way that can be of benefit to students and teachers rather than to cutting-edge researchers.

\section{REFERENCES}

Breyer, S. (1970); 'The Uneasy Case for Copyright: A Study of Copyright in Books, Photocopies, and Computer Programs', Harvard Law Review, 84, 281-351.

Coase, R. (1960), 'The Problem of Social Cost', Journal of Law and Economics, 3, 1-44.

Handke, C. and R. Towse (2008), 'Economics of Copyright Collecting Societies', International Review of Intellectual Property and Competition Law, 38(8), 937-57.

Hurt, R. and R. Schuchman (1966), 'The Economic Rationale of Copyright', American Economic Review, May, 421-32.

Liebowitz, S. and R. Watt (2006), 'How Best to Remunerate Creators in the Market for Music: Copyright and its Alternatives', Journal of Economic Surveys, 20(4), 513-45.

Towse, R., C. Handke and P. Stepan (2008), 'The Economics of Copyright Law: A Stocktake of the Literature', Review of Economic Research on Copyright Issues, 5(1), 1-22.

Plant, A. (1934), 'The Economic Aspects of Copyright in Books', Economica, 1(2), 167-95. 
Richard Watt - 9781849808538 Downloaded from PubFactory at 04/26/2023 02: 05: 04PM via free access 